\title{
Does Personality Matter in Leadership: Impact of Big Five Personality Traits on Ethical Leadership Behaviour of Middle Managers in Sri Lanka
}

\author{
W.S. Chandrasekara ${ }^{1}$ \\ ${ }^{1}$ Institute of Human Resource Advancement \\ University of Colombo \\ SRI LANKA \\ sagara@ihra.cmb.ac.lk ${ }^{1}$
}

\begin{abstract}
There are many studies on the consequences of ethical leadership, however, it is hard to find the traits of leaders and their influence on ethical leadership. Therefore, this research the aims to explore the role of a leader's personality in ethical leadership behaviour. Consequently, this research explores the effects of each Big Five Personality traits on Ethical Leadership behaviour. Therefore, it was hypothesized that Agreeableness, Conscientiousness, Openness to Experience, and Extraversion influence on ethical leadership behaviour positively whereas Neuroticism effects on ethical leadership behaviour negatively. 400 sample was selected. 200 respondents were selected from students of Bachelor of Labour Education (BLE) program at the Institute of Human Resource Advancement (IHRA) University of Colombo. All of them are employees. Parallelly, their leaders or supervisors were included in the sample. It was used a cross-sectional design for data collection. Leader of each respondent was asked to complete the Big Five Inventory (BFI) to measure the personality of leaders and employees were asked to complete the Ethical Leadership questionnaire to measure their insights against ethical behaviour of their leaders/superiors. Only one employee was selected if more than one employee work under the same leader/supervisor. Findings indicated that the Agreeableness, Conscientiousness, Openness to Experience and Extraversion significantly and positively effect on ethical leadership whereas the Neuroticism effects significantly and negatively on ethical leadership. These results suggest the importance of four personality traits respectively, Agreeableness, Conscientiousness, Openness to Experience, and Extraversion to become an ethical leader. Therefore, this study support for better understanding of the importance of the role of individual personality differences in leadership behaviour. Hence, the findings of this study could be considered to improve the leadership personality traits which help for ethical leadership behaviour that employees admire and thereby improve the performance of workers in organizations.
\end{abstract}

Keywords: Agreeableness, Conscientiousness, Openness to Experience, Extraversion, Neuroticism, Ethical Leadership 


\section{INTRODUCTION}

Personality is a set of invisible qualities and performance that last comparatively stable range of behaviours responding to distinctive things existing in the situations (Barrick \& Mount, 1991). Relationship between personality and leadership is well researched (Bligh, 2011; Kalshoven, Den Hartog, \& De Hoogh, 2011; McCrae \& Costa, 1987). For the first time, personality characteristics were classified into five categories as Extroversion or Surgency, agreeableness, Conscientiousness, culture, and emotional stability by Tupes and Christal (1961). Later by Norman (1963), personality traits were branded into five categories as Extraversion, Agreeableness, Conscientiousness, Neuroticism, and Openness to Experience and ladled as Big Five factors. The big five personality trait factors explain the construction of personality traits with five factors of Extraversion, Agreeableness, Conscientiousness, Neuroticism, and Openness to Experience (Digman, 1990). Numerous studies have done on big five personality traits and different types of leader behaviour (De Hoogh, Den Hartog, \& Koopman, 2005; Digman, 1990). Ethical personalities of a leader have a positive impact on subordinate's behaviour and it has a positive impact on organizational performance (Trevino, Hartman, \& Brown, 2000). Identifying personality types correlated with ethical leadership is important as it affects employee behaviour and organizational performance. There are numerous researches on the relationship of personality and ethical behaviour of the leader (Brown et al. 2005; Digman, 1990; Trevino, Hartman, \& Brown, 2000). These research findings prove that personality traits have a significant impact on ethical leadership phenomenon. In numerous studies, openness and conscientiousness personality traits are found positively impact on leadership (Walumbwa and Schaubroeck, 2009; Brown et al. 2005).

Leadership is the main faucal force to achieve organizational aims and objectives. In leadership research, personalities were defined as to be inborn or genetic qualities of the people. Especially, ethical leadership provide the favourable working climate for the employees to perform well in their roles (Brown \& Treviño, 2006). Numerous studies found that personality traits influence on leaders' behaviour (Bono \& Judge, 2004; McCrae \& Costa, 1987). Leader's positive influence on subordinates is the greatest motivation for employees to perform their optimal level and achieve organizational goals (Mihalcea, 2014). For years, many researchers have argued whether personality characteristics are significant predictors of emergence Or effectiveness of leadership (Zaccaro, 2007; Lord, DeVader, \& Alliger, 1986). This research study addresses the question of why some leaders influence their subordinated to perform well through ethical manner while some are using unethical manner to influence subordinates to perform well. Personality characteristics may explain this question. Investigating the personality 
factors that effect on ethical leadership is important because if the organization knows the most suitable personality of leader that influence on employees for best performance, the organization can influence in many stagers such as the selection of leaders, giving guidance and training for them, and development of ethical leadership qualities.

\subsection{Big Five Personality and Ethical Leadership}

Characteristics of ethical leaderships are mindfulness of others, thoughtful, honest, unselfish, kind, ethical, inner locus of control, positive, and supportive (Walumbwa, et al., 2011; Toor \& Ofori, 2009). Ethical leadership is the normatively suitable behaviour through individual actions and interpersonal relationships, and promotion of such behaviour to subordinates through two-way interaction, reinforcement, and decision-making (Brown et al., 2005). Brown et al. (2005) labelled the ethical leadership behaviour as "normatively appropriate behaviours" which include openness, honesty, reliability and truthfulness. Ethical leaders talk about ourselves, they ask what we can do, how we live and how we could improve our living standers (Chen \& Hou, 2016). High socially accountable leaders are apparent as more ethical leaders (De Hoogh \& Den Hartog, 2008). Ethical values in leadership are found to be one of the most positive effects on employees' performance in organizational level (Kanungo, 2001). Trevino et al. (2000), found two indicators of ethical leadership, moral person, and moral manager. Measurements of moral person are qualities of a leader such as honesty, trustworthiness, fairness in interactions with their subordinates. A moral person has ethical values and professional values, he or she can deserve a reputation as a reasonable and kind leader. A moral manager is a person who encourages and promote ethical behaviour and conduct at the organization. Such people demonstrate the ethical performance of them and they encourage their subordinates to behave ethically. Moral manager practise rewards and punishment to promote such ethical behaver in the organization. He or she must be a role model for their subordinates. Measurements of a moral person and moral manager are essential to be perceived as an ethical leader by subordinates (Trevino et al., 2000). Ethical leaders exhibit the benefits of ethical conduct as well as the cost of unethical conduct of employees. Such leaders establish perfect standards and practice of rewards as well as reasonable punishment to keep employees responsible for their behaviour (Treviño, Brown, \& Hartman, 2003). Ethical leadership positively and significantly correlated with employee commitment (Chen \& Hou, 2016). According to literature, understanding leadership is multifaceted and need more studies to discover the impact of personality on ethical leadership (Brown \& Treviño, 2006). According to ethical leadership theory, ethical leaders "provide followers with voice" and employees are encouraged to work rationally when leaders create a fair work climate in the organization (Brown et al., 2005). Ethical leaders express ethical values to subordinates. Due to positive conduct of behaviour of the ethical leaders, employees are 
not reluctant to report their problems and issues to their leaders (Brown et al., 2005), this practice help for better job performance. Therefore, this study aims to investigate the impact of big five personality traits on ethical leadership.

\subsubsection{Agreeableness and Ethical Leadership}

Agreeableness is a propensity for an individual to be accommodating of others, ratifying social norms, and trusting of others (Northouse, 2015). Dimensions of agreeableness are caring, gently, honesty, and sincere (Goldberg, 1990). People with agreeableness traits are defined as helpful, kind, gentle, honest, worm, and fair to others (Bono \& Judge, 2004; Costa \& McCrae, 1992). Agreeableness is an essential leader characteristic for creating a justice environment in the workplace (Mayer, Nishii, Schneider, \& Goldstein, 2007). Agreeableness positively relates to ethical leadership (Brown \& Treviño, 2006; Walumbwa \& Schaubroeck, 2009). This indicates that leaders with great agreeableness are expected to handle subordinates in an unbiased and humble way. Such leaders positively treat employees in all aspects. Agreeableness positively correlates with other positive types of leadership styles, such as transformational leadership style (Bono \& Judge, 2004) and ethical form of leadership (Kalshoven, Den Hartog, \& De Hoogh, 2011). It is assumed that people with greater on agreeableness is positively correlated with ethical leadership behaviour. Hence, the following hypothesis will be established;
Hypothesis 1: Agreeableness has a positive significant impact on ethical leadership behaviour.

\subsubsection{Conscientiousness and Ethical Leadership}

Conscientiousness is the most generally researched personality traits amid big five-factor theory (Bono \& Judge, 2004). The conscientiousness comprises two main features, responsibility and ability to work hard and meet challenges (Digman, 1990). People with greater conscientious tend to think seriously before doing something and follow ethical responsibilities and perceived duties (Costa \& McCrae, 1992). People with conscientious trait tend to have a high level of moral responsibility and respect for their obligations and responsibilities. They respect for genuineness and trustworthiness. they are not easily degraded by others. Conscientious people are transparent and reasonable (Kalshoven, Den Hartog, \& De Hoogh, 2011). Characteristics of conscientiousness persons are vigilant, consistent, systematic, realistic, motivated, and reasonable (McCrae \& Costa, 1987). This propensity indicates a relationship between conscientiousness and the behavior array that is obligatory become an ethical leader among employees. Workforces are more likely to do the correct thing for them as well as others, for the organization due to leader conscientiousness personality traits such as responsibility, thoughtfulness, hardworking, and fairness (Moon, 2001). Leaders with conscientiousness may be more expected to communicate strong and clear principles and morals for ethical 
behaviour to their employees. Conscientiousness positively relates to ethical leadership (Brown \& Treviño, 2006; Walumbwa \& Schaubroeck, 2009). Hence, the following hypothesis will be established;

Hypothesis 2: Conscientiousness has a positive significant effect on ethical leadership behaviour.

\subsubsection{Openness to experience and Ethical Leadership}

People with greater openness to experience are innovative, imaginative, multifaceted, and logical (McCrae \& Costa, 1987). Openness to experience is defined as a propensity to have effective creativity, and academic inquisitiveness and readiness to contemplate new viewpoints and apply innovative things, they tend to enthusiastically seek out various experiences that include different of views and thoughts (Costa \& McCrae, 1992). According to Bono and Judge (2004), individuals with greater openness to experience are emotional, academically inquisitive and involve in different ideas and insight which are required to be ethical leader. They are more intelligent inspired, imaginative, and helpful to others (Silvia, Nusbaum, Berg, \& Martin, 2009). Many studies found a positive relationship between Openness to Experience and Ethical Leadership. Based on the above arguments the following hypothesis will be proposed;

Hypothesis 3: Openness to experience has a positive significant impact on ethical leadership behaviour.

\subsubsection{Neuroticism and Ethical Leadership}

Neuroticism or emotional instability is the propensity to practice a mixture of disruptive feelings and beliefs or propensity to develop negative insights. Neuroticism has negatively correlated with ethical leadership due to its negative responsive factor. Individuals with greater neuroticism personality tend to display more anger, unconfident, worries, irritation, and frustration and they are more vulnerable to stress than low-neurotic individuals (Costa \& McCrae, 1992). Individuals with great neuroticism personality are less possible to become leaders (Hogan, Curphy, \& Hogan, 1994). Leaders with neurotic personality are less likely to become role models for employees (Bono \& Judge, 2004). According to a research done by Judge, Erez, Bono and Thoresen (2002b), individuals with neurotic personality are having lower self-esteem and self-efficacy. They experience a greater degree of harmful effect and become annoyed easily by others, and are more likely to turn to unsuitable coping strategies (McCrae $\&$ Costa, 1987). Leaders with a high level of neuroticism tend to have undesirable sentiments, such as nervousness, and irritation more frequently and more strongly (Brown and Treviño, 2006). Neurotic people are less possible to become an ethical leader, as such individuals hold "thinskinned and hostile toward others". People with these traits hard to become an effective role model leadership (Brown and Treviño, 2006).

People with negative traits are low effective leaders. Thus, leaders with a 
greater level of neuroticism may not act ethically.

Hypothesis 4: Neuroticism has a negative significant effect on ethical leadership behaviour.

\subsubsection{Extraversion and Ethical Leadership}

Compassion, sociability, talkativeness, and assertiveness are the measurement of extraversion personality (Bligh, 2011; McCrae \& Costa, 1987). Dimensions of extraverts display the positive aspect of behaviour among their subordinates (Bono \& Judge, 2004). Further, they found that extraversion is the greatest and most constantly and positively associated with other types of leaderships such as charismatic and transformational leadership, which comprised with ethical leadership conduct (Bono \& Judge, 2004). A leader with extraversion personality is identified as 'leader like' due to their personality of optimistic views about the future (Hogan, Curphy, \& Hogan, 1994). Costa and McCrae (1992) define extraverts as a personality trait that demonstrate sociability and assertiveness and propensity to experience positive feelings. Individuals with greater extraversion personality tend to hold greater communication capacity and they can express their ideas very clearly and systematically (Dulebohn, Bommer, Liden, Brouer, \& Ferris, 2012). Based on the above literature, it is predicted that extraversion would promote ethical leadership;

Hypothesis 5: Extraversion has positive significant impact on ethical leadership behaviour.

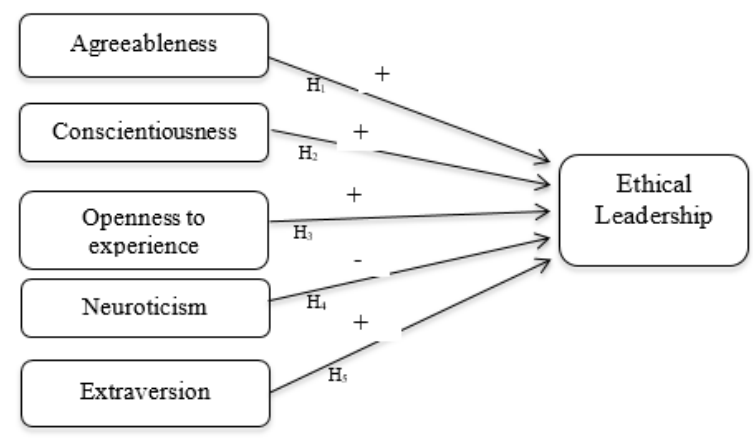

Figure 1. Hypothesized
Relationships.

Note: ' + ' indicates the positive effect $\&$ ' -' indicates the negative effect

\section{METHODS AND MEASURES}

\subsection{Sample and Research Design}

The sample was selected from students of Bachelor of Labour Education (BLE) program at the Institute of Human Resource Advancement (IHRA), the University of Colombo, Sri Lanka. All of them are employees. They have been employing more than at least two more years (some of them have been working for more than 10 to 15 years) in the private or public sector. They do the studies while they work to enhance their skills and capacities. 200 respondents were selected based on a random sampling system. There are more females than males in the BLE degree program. Hence, 120 female and 80 males were selected from all the years of the degree program. 200 leaders of the respondents as well were included in the sample. It was used a cross-sectional design for data collection. Leader of each respondent 
was asked to complete the Big five inventory questionnaire to measure the personality of leaders and respondents were asked to complete the Ethical Leadership questionnaire to measure their insights about the ethical conducts of their superiors. Before the sample selection, the consent of the employees and leaders were checked whether they agree to join the survey. Employees who work under the same leader were excluded.

\subsection{Measures}

\subsubsection{Big Five Personality}

Big five inventory was used to measure the personality of leaders. It was used the 44-item model developed by John, Donahue, \& Kentle,(1991) to measure the elements of big five personality trait. Agreeableness was measured based on the nine-item subscale. A example element involved 'I see myself as somebody who is supportive and kind.' Conscientiousness was assessed by seven elements. An example element is 'I see myself as somebody comprehensive employment'. Extraversion was assessed by six elements subscale, and an example element involved 'I see myself as somebody chatty.' Openness was assessed by 10 items subscale. An example element is 'I see myself as somebody creative'. Neuroticism was assessed with six items sub-scale. A example element is 'I see myself as somebody who is miserable.'

\subsubsection{Ethical Leadership}

Ethical leadership was measured using the 10-item Ethical Leadership Scale (ELS) developed by Brown et al. (2005) to measure insights of employees about the ethical conducts of their leaders/supervisors. It was rated on a 5-point Likert scale, 1= strongly disagree to $5=$ strongly agree . Sample items include 'My boss discusses business ethics and standards with the staff', 'My boss listens to employees'.

\section{RESULTS}

Reliability of the scales used in the research was tested through calculating Cronbach Alpha Coefficient. According to Taber (2018), Cronbach's Alpha Coefficient of a measurement should be exceeding 0.70 for validation. The Cronbach's Alpha Coefficient of the six scales used in this research, Extraversion, Agreeableness, Conscientiousness, Neuroticism, Openness to Experience, and Ethical Leadership are roughly greater than 0.70 (Table 01). It shows that each of scales used in the study has internal reliability as values of the coefficient of all the scales are exceeding the threshold level of the reliability. 
Table 1. Reliability of the Scales Used in the Research

\begin{tabular}{llllllllll}
\hline Variables & $\begin{array}{l}\text { Chi- } \\
\text { square }\end{array}$ & RMSEA & GFI & AGFI & CFI & TLI & NFI & AVE & CR \\
\hline Extraversion & 3.463 & 0.052 & 0.834 & 0.941 & 0.936 & 0.822 & 0.838 & .51 & .87 \\
\hline Agreeableness & 3.314 & 0.075 & 0.831 & 0.922 & 0.917 & 0.861 & 0.821 & .56 & .88 \\
\hline Conscientiousness & 3.215 & 0.063 & 0.835 & 0.857 & 0.991 & 0.882 & 0.854 & .54 & .87 \\
\hline Neuroticism & 3.613 & 0.052 & 0.827 & 0.913 & 0.825 & 0.859 & 0.882 & .56 & .89 \\
\hline Openness to & & & & & & & & & \\
Experience & 3.522 & 0.067 & 0.884 & 0.963 & 0.931 & 0.821 & 0.876 & .57 & .82 \\
\hline Ethical Leadership & 3.652 & 0.051 & 0.892 & 0.931 & 0.74 & 0.831 & 0.836 & .54 & .86 \\
\hline
\end{tabular}

Means, Standard deviations (SD) for employees' responses and leaders' responses as well as inter-item correlations of all study variables are presented in Table 02.

Table 2. Mean, Standard Deviation, and Correlations of Study Variables

\begin{tabular}{|c|c|c|c|c|c|c|c|c|c|c|}
\hline & Construct & Employ & & Leaders & & & & & & \\
\hline & Construct & Mean1 & SD 1 & Mean2 & SD 2 & 1 & 2 & 3 & 4 & 5 \\
\hline 1 & Extraversion & 3.81 & 0.84 & 3.63 & 0.71 & & & & & \\
\hline 2 & Agreeableness & 3.97 & 0.65 & 3.14 & 0.84 & $.28 * *$ & & & & \\
\hline 3 & $\begin{array}{l}\text { Conscientiousn } \\
\text { ess }\end{array}$ & 2.84 & 0.92 & 3.81 & 0.66 & $.36 * *$ & $.27 * *$ & & & \\
\hline 4 & Neuroticism & 3.29 & 0.78 & 3.52 & 0.84 & $-.17 *$ & -.02 & $-.13 *$ & & \\
\hline 5 & $\begin{array}{l}\text { Openness to } \\
\text { Experience }\end{array}$ & 4.11 & 0.53 & 3.86 & 0.81 & $.31 * *$ & $.27 * *$ & $.29 * *$ & $\begin{array}{l}.38^{*} \\
*\end{array}$ & \\
\hline 6 & $\begin{array}{l}\text { Ethical } \\
\text { Leadership }\end{array}$ & 4.47 & 0.98 & 3.79 & 0.62 & $.41 * *$ & $.19^{*}$ & $.29 * *$ & $-.11 *$ & $.89 * *$ \\
\hline
\end{tabular}

Note: Mean1 \& SD1 of employee's questionnaire, Mean2 \& SD2 of leaders' questionnaire

\subsection{Hypothesis Testing}

As given in Table 03, regression analysis was conducted to test the hypothes to measure the effect of leader personality on ethical leadership behaviour. The findings indicated that Extraversion $(\beta=.259$, $\mathrm{p}>.05), \quad$ Agreeableness $\quad(\beta=.347$, $\mathrm{p}>.05)$, Conscientiousness $\quad(\beta=.253$, 
$\mathrm{p}>.05)$, Openness to Experience $(\beta=.374, \quad \mathrm{p}>.05)$ have a positive statistically significant effect on Ethical Leadership. Hence, the hypothesis 1, 2, 3, and 5 are accepted and extraversion, agreeableness, conscientiousness, and openness to Experience have a positive significant impact on ethical leadership behaviour. However, as expected, hypothesis 4 , Neuroticism $(\beta=-.285$, p>.05) has a negative statistically significant impact on ethical leadership behaviour will be accepted.

Table 3. Regression Analysis of Study Scales and Ethical Leadership

\begin{tabular}{lllll}
\hline & $\mathrm{R}^{2}$ & $\beta$ & $\mathrm{t}$ & $\mathrm{P}$ \\
\hline Extraversion & .194 & .259 & $2.18^{*}$ & 0.000 \\
\hline Agreeableness & .035 & .347 & $4.51^{* *}$ & 0.000 \\
\hline Conscientiousness & .182 & .353 & $3.89^{* *}$ & 0.000 \\
\hline Neuroticism & .142 & -.285 & $-3.46^{* *}$ & 0.000 \\
\hline Openness to Experience & .101 & .374 & $3.32^{* *}$ & 0.000 \\
\hline
\end{tabular}

\section{DISCUSSION}

This research study expected to explore the impact of big five personality traits, Extraversion, Agreeableness, Conscientiousness, Neuroticism, and Openness to Experience on Ethical Leadership conduct in Sri Lankan. It was found that four personality characteristics of leaders, Extraversion, Agreeableness, Conscientiousness, and Openness to Experience were positively and significantly related to employees' insights about their spurious as ethical leaders. This finding is in line with Walumbwa and Schaubroeck (2009), that there is a noteworthy association between the Big Five traits and ethical leadership. However, Neuroticism has a negative significant effect on ethical leadership. This result consists of Brown et al. (2005) finding that Neuroticism personality trait has a negative impact on ethical leadership. Line with the findings of Walumbwa and Schaubroeck (2009), agreeableness became most influential personality trait on ethical leadership. Thus, it can be concluded that more agreeable leaders are accepted by subordinators as ethical leaders. They treat subordinators in a kind-hearted and fair manner. According to previous they cooperative, authentic, decent, reliable, empathetic, and receptive. These conducts are crucial to be an ethical leader (Brown \& Trevino, 2006). Hypothesis 02, conscientiousness has a positive significant effect on ethical leadership behaviour is accepted. People with greater conscientious traits practise ethical responsibility. They care genuineness and trustworthiness. Such leaders are well methodical and accountable, such propensities indicate the relationship between 
conscientiousness and the conduct of the leader which essential to be an ethical leader.

There are a few limitations of this study. One is this research was limited to middle-level managers and supervisors. The sample size also is limited, 200 subordinates and 200 managers, altogether 400 respondents. Sample would have been increased. Hence, the generalization of the results of the research is limited. Though there are limitations, these findings have significant practical implications on employees' job performance, because the leader's personality has a positive significant effect on employee job performance (Chandrasekara, 2019). This research adds knowledge to the field by evaluating the effect of Big Five personality characteristics on ethical leadership. According to previous research, most influential personality traits are agreeableness and conscientiousness. It indicates the importance of personality traits when selecting a leader. When selecting leaders, it is needed to consider whether their behaviour is fair, powersharing and roles clarifying. In general, this study indicates the significance of better understanding of the role of individual personality differences in leadership behaviour. Further, indicate the importance of four personality traits respectively, Agreeableness, Conscientiousness, Openness to Experience, and Extraversion to be an ethical leadership behaviour. Supplementary, Neuroticism is found as a negative personality trait for an ethical leader that indicated as an avoiding personality for an ethical leader.
Hence, the findings of this study could be used to improve the ethical leadership personality that support employees job satisfaction and job performance of workers in organizations.

\section{REFERENCES}

Barrick, M., \& Mount, M. (1991). The big five personality dimensions and job performance: a metaanalysis. Personnel psychology, 44(1), 1-26.

Bligh, M. (2011). Personality theories of leadership; Encyclopedia of Group Processes and Intergroup Relations. Sage, 661-676.

Bono, J., \& Judge, T. (2004). Personality and transformational and transactional leadership:A meta-analysis. Journal of Applied Psychology, 89(5), 901-10.

Brown, M., \& Treviño, L. (2006). Ethical leadership: A review and future directions. The Leadership Quarterly, 17(5), 595-616.

Brown, M., Treviño, L., \& Harrison, D. (2005). Ethical leadership:A social learning perspective for construct development and testing. Organizational Behavior and Human Decision Processes, 97(2), 117-134.

Chandrasekara, W. (2019). Relationship among big five personality traits, job performance $\&$ job satisfaction: a case of school teachers in sri lanka. International 
Journal of Information, Business and Management, 11(2).

Chen, A., \& Hou, Y. (2016). The effects of ethical leadership, voice behavior and climates for innovation on creativity: A moderated mediation examination. The Leadership Quarterly, 27(1), 1-13.

Costa, P., \& McCrae, R. (1992). Four Ways Five Factors are Basic. Personality Individual Differences, 13, 653-665.

De Hoogh, A., \& Den Hartog, D. (2008). Ethical and Despotic Leadership, Relationships with Leader's Social Responsibility, Top Management Team Effectiveness and Subordinates' Optimism: A Multi-Method Study. The Leadership Quarterly, 18, 297-311.

De Hoogh, A., Den Hartog, D., \& Koopman, P. (2005). Linking the Big Five-Factors of Per- sonality to Charismatic and Transactional Leadership; Perceived Dynamic Work Environment as a Moderator. Journal of Organizational Behavior, 26, 839-865.

Digman, J. (1990). Personality Structure: The Emer- gence of the Five-Factor Model. Annual Review of Psychology, 41, 417440.

Dulebohn, J., Bommer, W., Liden, R., Brouer, L., \& Ferris, G. (2012). A meta-analysis of antecedents and consequences of leader-member exchange integrating the past with an eye toward the future. Journal of Management, 38(6), 17151759.

Fabrigar, L., MacCallum, R., \& Wegener, D. (1999). Evaluating the use of exploratory factor analysis in psychological research. Psychological Methods, 4(3), 272-299.

Goldberg, L. (1990). An Alternative Description of Personality: The Big Five Factor Structure. Journal of Personality and Social Psychology, 59, 1216-1229.

Hogan, R., Curphy, G., \& Hogan, J. (1994). What we Know About Leadership: Effectiveness and Personality. American Psychologist, 94, 493-504.

John, O., Donahue, E., \& Kentle, R. (1991). The "Big Five" Inventory -Versions $4 a$ and 5a. Berkeley: Institute of Personality and Social Research.

Judge, T., Erez, A., Bono, J., \& Thoresen, C. (2002). Are Measures of Self-Esteem, Neuroticism, Locus of Control, and Generalized Self-Efficacy Indicators of a Common Core Construct? Journal of Personality and Social Psychology, 83(3), 693-710.

Kalshoven, K., Den Hartog, D., \& De Hoogh, A. (2011). Ethical leader behavior and Big Five factors of personality. Journal of Business Ethics, 100(2), 349-366. 
Kanungo, R. (2001). Ethical Values of Transactional and Transformational Leaders. Canadian Journal of Administrative Sciences, 18, 257265.

Lord, R., DeVader, L., \& Alliger, G. (1986). A meta-analysis of the relation between personality traits and leadership perceptions: An application of validity generalization procedures. Journal of Applied Psychology, 71, 402-410.

Mayer, D., Nishii, L., Schneider, B., \& Goldstein, H. (2007). The Precursors and Products of Justice Cli- mates: Group Leader Antecedents and Employee Attitudinal Consequences. Personnel Psychology, 60, 929963.

McCrae, R., \& Costa, P. (1987). Validation of the five-factor model of personality across instruments and observers. Journal of Personality and Social Psychology, 52(1), 81-90.

Mihalcea, A. (2014). Leadership, personality, job satisfaction and job performance. Social and Behavioral Sciences, 127, 443 447.

Moon, H. (2001). The Two Faces of Conscientiousness: Duty and Achievement Striving in Escalation of Commitment Dilemmas. Journal of Applied Psychology, 86, 533-540.
Norman, W. (1963). Toward an adequate taxonomy of personality attributes: Replicated factor structure in peer nomination personality ratings. Journal of Abnormal and Social Psychology, 66(6), 574-583.

Northouse, G. (2015). Leadership: Theory and practice (7th Ede). Thousand Oaks: CA: SAGE.

Silvia, P., Nusbaum, E., Berg, C., \& Martin, C. (2009). Openness to experience, plasticity, and creativity: Explor- ing lowerorder, high-order, and interactive effects. Journal of Research in Personality, 43, 1087-1090.

Taber, K. (2018). The Use of Cronbach's Alpha When Developing and Reporting Research Instruments in Science Education (Vol. 48). Cambridge: University of Cambridge.

Toor, S., \& Ofori, G. (2009). Ethical Leadership: Examining the Relationships with Full Range Leadership Model, Employee Outcomes, and Organizational Culture. Journal of Business Ethics, 90, 533-547.

Treviño, L., Brown, M., \& Hartman, L. (2003). A qualitative investigation of perceived executive ethical leadership: Perceptions from inside and outside the executive suite. Human Relations, 56(1), 5-37.

Trevino, L., Hartman, L., \& Brown, M. (2000). Moral person and moral manager: How executives 
develop a reputation for ethical leadership. California Management Review, 42(4), 128142.

Tupes, E., \& Christal, R. (1961). Recurrent personality factors based on trait ratings. Lackland Airforce Base: USAF ASD Tech.

Walumbwa, F., \& Schaubroeck, J. (2009). Leader personality traits and employee voice behavior: Mediating roles of ethical leadership and work group psychological safety. Journal of Applied Psychology, 94(5), 12751286.
Walumbwa, F., Mayer, D., Wang, P., Wang, H., Workman, K., \& Christensen, A. (2011). Linking ethical leadership to employee performance: The roles of leadermember exchange, self-efficacy, and organizational identification. Organizational Behavior and Human Decision Processes, 115, 204-213.

Zaccaro, S. (2007). Trait-based perspectives of leadership. American Psychologist, 62, 6-16. 